\title{
Transient Intrauterine Hypotension: Effect on Newborn Rat Brain
}

\author{
R. ANIL APAK, $\dagger$ BANU ANLAR, PERGIN ATILLA, AND NUR ÇAKAR \\ Department of Pediatric Neurology [R.A.A., B.A.], and Department of Histology-Embryology [P.A., N.Ç,], \\ Hacettepe University, Ankara, Turkey 06100.
}

\begin{abstract}
ABS
Intrauterine perfusion failure can cause cerebral malforma-
tions. We investigated the effect of transient maternal hypotension on newborn rat brain by inducing hypovolemic hypotension for $2.5 \mathrm{~h}$ during early embryonic day 7 (E7) or late (E15) gestation in pregnant rats. We found an increase in the number of TUNEL-positive cells within the periventricular germinative matrix in pups subjected to early gestational hypotension and within the cerebral cortex in those subjected to late gestational hypotension in comparison to sham control animals. These results suggest that episodic maternal hypovolemic hypotension may affect the fetal brain, and apoptotic mechanisms may mediate this effect. (Pediatr Res 49: 45-49, 2001)
\end{abstract}

\author{
EH, early hypotension \\ EC, early control \\ LH, late hypotension \\ LC, late control \\ BP, blood pressure \\ TUNEL, terminal deoxynucleotidyl-mediated dUTP nick end \\ labeling \\ PVGZ, periventricular germinative zone
}

Hypoxia and perfusion failure during pregnancy can be associated with fetal brain malformations $(1,2)$. A prospective follow-up study of pregnancies complicated by maternal shock or blood loss revealed an increased incidence of polymicrogyria, hydranencephaly, or porencephaly in the infants (3). Transient hypotensive episodes without blood loss, relatively common events during pregnancy, are also considered potentially harmful to the fetus. However, little clinical data exist on their association with brain malformations (3). In particular, the consequences of early gestational (wk 1-16) hypotension have not been investigated. The pathophysiological events leading to fetal malformations following perfusion failure are also unclear: in addition to necrosis, they may include the induction or acceleration of apoptosis. In this experimental study, we investigated the possible consequences of intrauterine transient hypoperfusion on the newborn's brain by producing early and late gestational hypotension in pregnant rats, and examining histology and apoptosis in their pups.

Received October 7, 1999; accepted May 7, 2000.

Correspondence: Banu Anlar, M.D., Hacettepe University, Department of Pediatric Neurology, 06100 Ankara, Turkey.

This study was supported by Hacettepe University Research Fund and Child Neurology Society, Ankara, Turkey.

$\dagger$ Deceased.

\section{METHODS}

Gestational hypotension. Twelve 3-mo-old pregnant Wistar rats were studied in four groups: EH group (hypotension applied on E7, $n=3$ ), LH group (hypotension on E15, $n=3$ ), and their corresponding control groups (EC and LC, $n=3$ each). They were subjected to transient hypotension by femoral artery catheterization. Briefly, rats were anesthetized following an overnight fasting by i.p. $50 \mathrm{mg} / \mathrm{kg}$ ketamine (Ketalar ${ }^{\circledR}$, Eczacibasi, Istanbul, Turkey) and $8 \mathrm{mg} / \mathrm{kg}$ xylasine (Rompun ${ }^{\circledR}$, Bayer, Istanbul, Turkey), put into Fowler position, and left to spontaneous breathing. Rectal temperature was kept constant between 36.5 and $37.5^{\circ} \mathrm{C}$ by a homeothermic blanket. The femoral artery was dissected by a vertical incision in the femoral region, hooked from the proximal and ligated at the distal end. A 1-mm incision was made in the middle of the artery and a heparinized Silastic $2 \mathrm{~F}$ catheter was inserted. The catheter was connected to a mercury manometer by a stopcock. The proximal hook was then released and blood was allowed to fill the catheter and reach the manometer. After an oscillation and stable BP was obtained, approximately $1 \mathrm{~mL}$ blood was slowly drawn into a heparinized syringe until $50 \%$ reduction in $\mathrm{BP}$ was achieved. This syringe was kept at $37^{\circ} \mathrm{C}$. The lowered BP level was maintained for $2.5 \mathrm{~h}$. At the end of this period, blood was reinfused and the femoral artery was ligated. Control groups were subjected to the whole procedure except 
hypotension. Rats were allowed to complete the normal course of pregnancy.

The study was approved by the Institutional Animal Ethics Committee.

Histopathological examination and TUNEL staining. Within $24 \mathrm{~h}$ of delivery, two rat pups from each mother were randomly selected by a technician. They were decapitated, the brain was fixed in $10 \%$ buffered formalin, embedded in paraffin, dehydrated through graded alcohol concentrations, and consecutive 5- $\mu \mathrm{m}$ transverse sections passing through the orbital level were taken.

Brain sections were examined with hematoxylin-eosin (H\&E) under $40 \times$ magnification for cortical architecture, ventricular integrity, and the presence of necrosis and hemorrhage. Thickness of germinal matrices at the thickest area of the periventricular zone, and frontal, parietal, and occipital cortices were measured by a $40 \times$ objective and eyepiece with $1-\mathrm{mm}$ grids. Three measurements were made for each region. Values were expressed as mean of frontal, parietal, and occipital cortex measurements $\pm \mathrm{SD}$.

DNA fragmentation was evaluated by the TUNEL method (4). Briefly, poly-L-lysine-coated slides were deparaffinized by overnight incubation, hydrated in decreasing concentrations of ethanol, and incubated with proteinase $\mathrm{K}(20 \mathrm{mg} / \mathrm{mL}, 15 \mathrm{~min}$, ApopTag Kit; Appligene Oncor, France). Endogenous peroxidase was blocked in $35 \%$ hydrogen peroxide $(15 \mathrm{~min}$, room temperature). Nick-end labeling was carried out by a digoxygenin-dUTP containing TdT solution. After washing with buffer, peroxidase-conjugated anti-digoxygenin was added and slides were incubated at room temperature for $30 \mathrm{~min}$. Staining was visualized with $0.05 \%$ diaminobenzidine. Methyl green was used for background staining. TUNEL-positive cells, identified as brownish cells having intense basophilia and shrinkage, peripheral condensation, and nuclear fragmentation into uniformly dense basophilic masses were detected and counted by two blinded examiners. The average of their counts was recorded.

Antineurofilament and anti-S-100 antibodies (Sigma Chemical Co., St. Louis, MO, U.S.A.), staining neural and glial cells respectively, were used to characterize the cells in the cerebral regions examined. A normal adult intestinal wall biopsy including the myenteric plexus and adult peripheral nerve were used as positive control tissues.
Table 1. Weight, duration of gestation, and litter size of the rat groups

\begin{tabular}{cccc}
\hline Groups & $\begin{array}{c}\text { Weight }(\mathrm{g}) \\
(\text { mean } \pm \text { SD) }\end{array}$ & $\begin{array}{c}\text { Duration of } \\
\text { gestation (days) }\end{array}$ & Number of pups \\
\hline EH $(n=3)$ & $206.6 \pm 12.5$ & $27.0 \pm 0.5$ & $9.6 \pm 1.1$ \\
EC $(n=3)$ & $201.6 \pm 12.5$ & $27.0 \pm 1.0$ & $10.0 \pm 1.0$ \\
LH $(n=3)$ & $202.0 \pm 2.6$ & $27.3 \pm 1.0$ & $10.3 \pm 0.5$ \\
LC $(n=3)$ & $221.6 \pm 10.4$ & $26.6 \pm 0.5$ & $11 . \pm 1.5$ \\
\hline
\end{tabular}

Table 2. Cortical and periventricular germinative zone thickness: mean of the frontal, parietal, and occipital measurements

\begin{tabular}{|c|c|c|c|c|}
\hline \multirow[b]{3}{*}{ Pups } & \multicolumn{4}{|c|}{ Thickness $(\mathrm{mm}) \pm \mathrm{SD}$} \\
\hline & \multicolumn{2}{|c|}{$\begin{array}{l}\text { Periventricular } \\
\text { germinative zone }\end{array}$} & \multicolumn{2}{|c|}{ Cortex } \\
\hline & Right & Left & Right & Left \\
\hline $\mathrm{EH}(n=6)$ & $7.3 \pm 0.5$ & $7.0 \pm 0.6$ & $46.0 \pm 0.6$ & $44.6 \pm 1.0$ \\
\hline $\mathrm{EC}(n=6)$ & $6.8 \pm 0.8$ & $6.8 \pm 0.7$ & $46.0 \pm 0.8$ & $45.5 \pm 1.3$ \\
\hline $\mathrm{LH}(n=6)$ & $7.0 \pm 0.8$ & $6.8 \pm 0.7$ & $45.8 \pm 0.9$ & $46.0 \pm 0.6$ \\
\hline $\mathrm{LC}(n=6)$ & $6.8 \pm 0.7$ & $6.6 \pm 0.7$ & $45.8 \pm 0.7$ & $45.6 \pm 0.5$ \\
\hline
\end{tabular}

Mann-Whitney $U$ test was used for statistical comparison of the cell counts.

\section{RESULTS}

Average weight, duration of gestation and litter size of the groups are given in Table 1. No stillbirths or neonatal deaths occurred in any of the groups.

The thickness of the germinal matrix and mean cortical tissue was similar in control and hypotension groups, and in the right and left hemispheres in each pup $(U=11.500, p=0.227$; $U=9.000, p=0.138$ ) (Table 2). On microscopic evaluation, no alteration of cortical layering, hemorrhage, or inflammatory infiltration was observed. Visible nuclei and nucleoli and intact cytoplasms in cortical cells excluded the occurrence of significant necrosis.

The number of TUNEL-positive cells showing nuclear condensation, blebbing, and fragmentation was significantly higher in the periventricular matrix of the EH group compared with the LH and control groups $(p=0.01)$ (Table 3, Fig. $1 A-D$ ). On the other hand, the late hypotension group had significantly more TUNEL-positive cells than all other groups in the parietooccipital region, observed in clusters within the cortical plate $(p=0.005$, Table 4, Fig. $2 A-D)$.

Table 3. Number of TUNEL-positive cells within the periventricular germinative zone (PVGZ) and cerebral cortex in the EH and EC groups

\begin{tabular}{|c|c|c|c|c|c|c|c|c|}
\hline \multirow[b]{2}{*}{ Pup \# } & \multicolumn{2}{|c|}{ PVGZ (n) } & \multicolumn{6}{|c|}{ Cerebral cortex $(n)$} \\
\hline & Right & Left & $\mathrm{R}$ frontal & $\mathrm{R}$ parietal & R occipital & $\mathrm{L}$ frontal & L parietal & L occipital \\
\hline EH1 & 12 & 16 & 1 & 1 & - & 1 & 1 & - \\
\hline EH3 & 19 & 20 & 1 & - & 1 & 1 & 1 & - \\
\hline EH4 & 11 & 13 & 2 & 1 & - & 1 & 1 & 1 \\
\hline EH5 & 14 & 11 & - & 2 & 1 & 2 & - & 1 \\
\hline EH6 & 10 & 12 & 1 & 1 & 1 & 1 & 1 & 1 \\
\hline EC3 & 4 & 2 & - & 1 & 1 & - & - & 3 \\
\hline EC4 & 2 & 3 & 1 & - & 1 & 1 & 1 & 1 \\
\hline EC5 & 3 & 3 & 2 & 1 & - & 1 & 1 & 1 \\
\hline EC6 & 2 & 2 & 1 & 1 & 1 & - & - & 1 \\
\hline
\end{tabular}



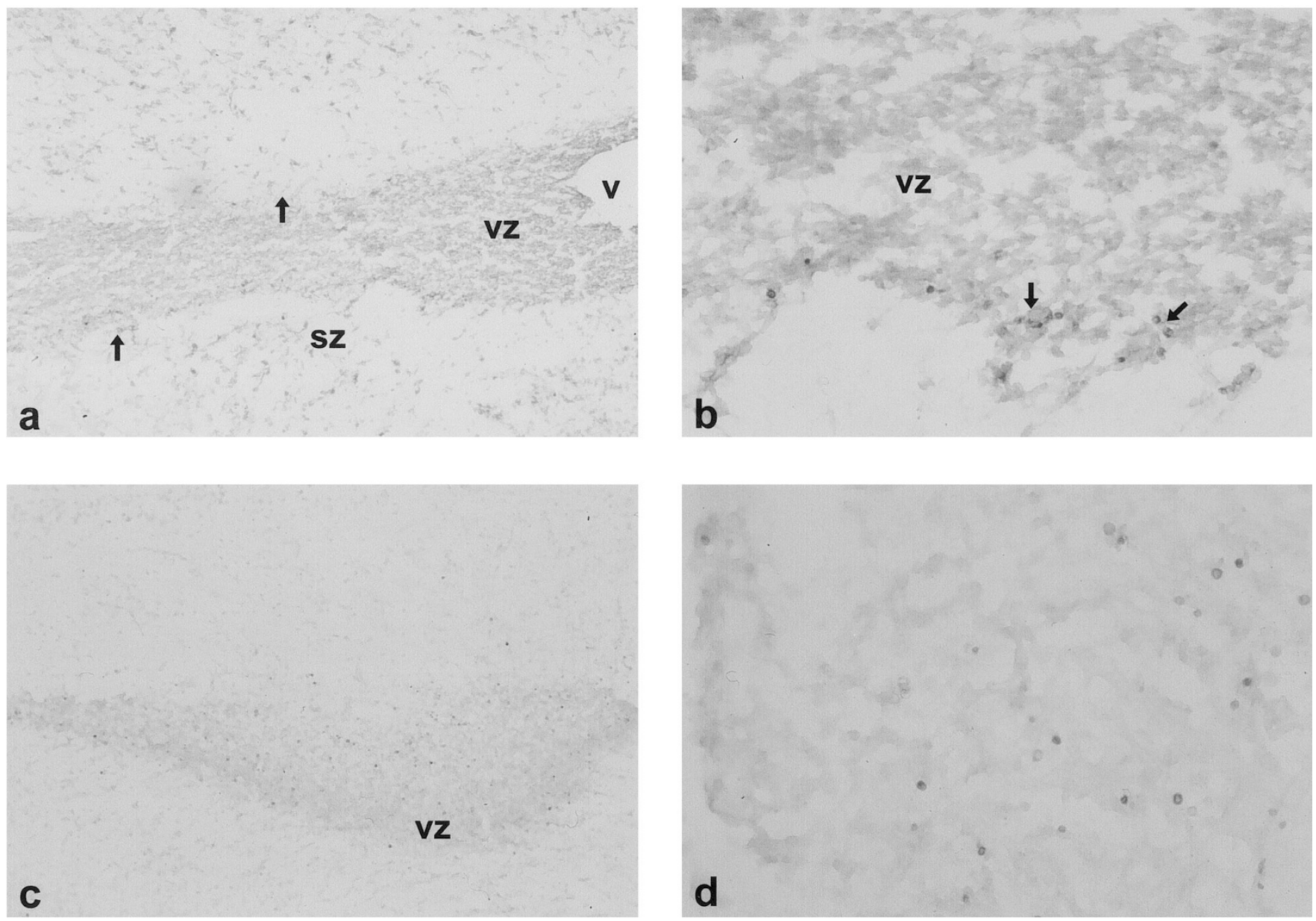

Figure 1. $(A, B)$. Periventricular germinative zone, EH group: TUNEL-positive cells (arrows) at the border between ventricular $(v z)$ and subventricular $(s z)$ zones (original magnification $\times 100$ and $\times 400)$. $v$, ventricle. $(C, D)$ Early control group: the ventricular wall is observed at a tangential section. Fewer apoptotic cells, some with condensed nuclei, are observed at the same location.

Table 4. Number of TUNEL-positive cells within the periventricular germinative zone (PVGZ) and cerebral cortex in the LH and LC groups

\begin{tabular}{|c|c|c|c|c|c|c|c|c|}
\hline \multirow[b]{2}{*}{ Pup \# } & \multicolumn{2}{|c|}{ PVGZ (n) } & \multicolumn{6}{|c|}{ Cerebral cortex $(n)$} \\
\hline & Right & Left & $\mathrm{R}$ frontal & $\mathrm{R}$ parietal & R occipital & $\mathrm{L}$ frontal & $\mathrm{L}$ parietal & L occipital \\
\hline LH1 & 4 & 3 & 9 & 13 & 18 & 8 & 13 & 16 \\
\hline LH3 & 3 & 2 & 7 & 12 & 15 & 5 & 12 & 19 \\
\hline LH4 & 2 & 3 & 7 & 14 & 16 & 6 & 12 & 14 \\
\hline LH5 & 3 & 2 & 6 & 12 & 14 & 7 & 11 & 14 \\
\hline LH6 & 2 & 2 & 5 & 14 & 15 & 5 & 12 & 15 \\
\hline LC2 & 3 & 2 & 2 & - & 1 & 1 & - & 1 \\
\hline LC3 & 2 & 3 & 2 & - & 2 & 1 & 1 & 1 \\
\hline LC4 & 3 & 3 & 1 & 1 & - & 1 & 1 & - \\
\hline LC5 & 4 & 3 & - & 1 & 1 & - & - & 2 \\
\hline LC6 & 3 & 2 & 2 & - & - & 1 & - & 1 \\
\hline
\end{tabular}

Double immunohistochemistry with antineurofilament and anti-S100 antibodies on TUNEL-stained tissues did not give optimal morphologic results. We therefore examined adjacent sections with TUNEL and immunohistochemistry. The majority $(50 \%-75 \%$ in all sections) of periventricular TUNELpositive cells in the EH group were neurofilament and S-100 negative. Among cortical cells in the LH group, 50\% were neurofilament positive and all were S-100 negative. In control tissues stained during the same experiment, the myenteric plexus, endothelial cells, and Schwann cells were positive with these antibodies.

\section{DISCUSSION}

Apoptosis has been described in many regions of the vertebrate nervous system including rat cerebral cortex (5). It is a physiologic event starting with DNA fragmentation in early and late periods of development, which is also observed in our 

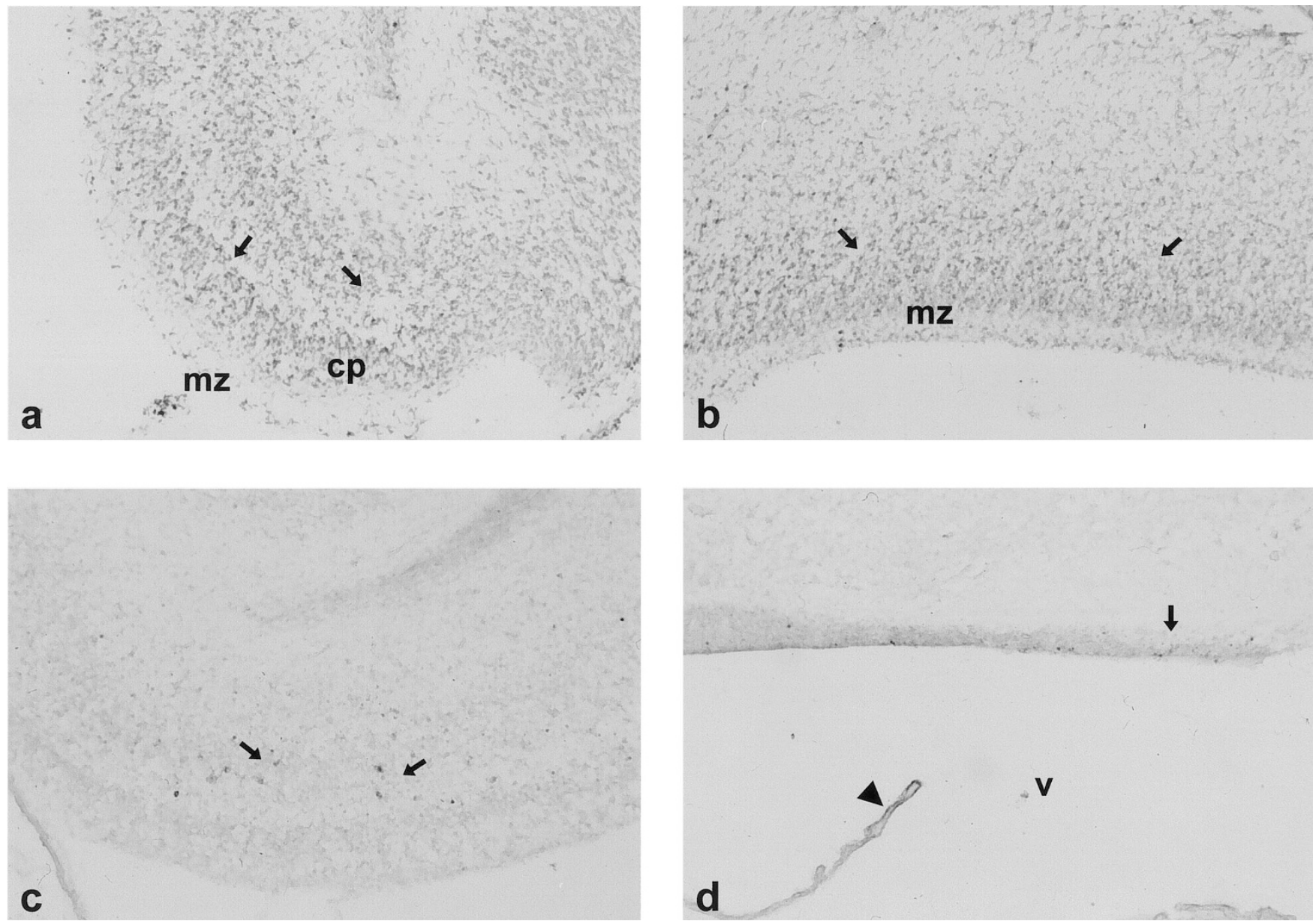

Figure 2. $(A, B)$ LH group: numerous TUNEL-positive cells in the occipitoparietal cortex. $m z$, marginal zone; $c p$, cortical plate. $(C, D)$ Late control group. Only few TUNEL-positive cells are observed in the $(C)$ occipital cortex, and $(D)$ ventricular zone. $V$, ventricle, arrowhead, choroid plexus. Background stained with methyl green. Original magnification $\times 100$.

control groups as scattered TUNEL-positive cells in the cortex and the periventricular region. On the other hand, rats subjected to intrauterine perfusion failure had markedly increased TUNEL positivity. They showed normal cortical architecture and no major cerebral malformations: this suggests that normal findings on routine histologic examination do not exclude the possibility of cerebral injury.

According to previous studies, transient near-term gestational hypotension may produce edema and necrosis of the fetal brain (6). On the other hand, mid-gestational umbilical cord occlusion in pregnant sheep for 10-20 min, although causing fetal hypotension, bradycardia, acidosis, and hypoxia, produced no cerebral abnormalities (7). These findings illustrate the effect of varying experimental conditions, such as the duration and degree of hypotension, on the type and extent of the damage. Short or mild hypotensive episodes where compensatory mechanisms suffice to maintain tissue perfusion may not produce any morphologic changes. The 2.5 -h episode used in our model corresponds to $1 \mathrm{~d}$ in human gestation, considered as a clinically significant period. A dose effect is possible in hypotension, as in toxin exposure where different doses of the same agent can cause necrosis or apoptosis (8). Severe maternal hypotension might result in necrosis and major damage in fetal brain, as reported after maternal anaphylaxis, whereas moderate hypotension might only increase the ongoing apoptosis (9). Our model is more likely to reproduce the latter. The timing of the insult is also important: immature neurons are more prone to apoptosis in hypoxia-ischemia (10). Two critical periods have been reported for cerebral effects of fetal perfusion failure: wk $20-24$ and the last $10 \mathrm{wk}$ of gestation. Hydranencephalic newborns have a history of perfusion failure around fetal wk 30. Mid-cortical laminar necrosis, cortical overfolding, and polymicrogyria have been associated with perfusion failure after wk 20 of pregnancy. On the other hand, placental insufficiency occurring near birth is known to result in periventricular leukomalacia, multifocal necrosis within the cerebral white matter, or peri- or intraventricular hemorrhage (3).

Apoptosis was originally defined as a morphologic term, and is ideally determined by the appearance of cells under the electron microscope. However, all methods for the detection of apoptosis have limitations, and the difficulty of searching apoptotic cells in large tissue sections by electron microscopy prompt many researchers to use the TUNEL method based on DNA fragmentation (4). As in our samples, morphologic features such as nuclear condensation, blebbing, and apoptotic bodies accompany TUNEL-positivity, and inflammatory changes are absent in this type of cell death. 
Difficulties have been reported in the identification of apoptotic cells as neuronal or glial under the light microscope during the developmental period (11). Specific stainings, including in vivo injection of cellular markers, may not always provide an answer due to the absence or transient expression of these markers and changes in cell phenotypes during development $(12,13)$. We interpreted the TUNEL-positive cells observed in the periventricular and cortical regions as neuroblasts and neurons, respectively, based on their size, appearance, localization, and immunostaining, which was negative for periventricular cells, indicating a less differentiated status, and neurofilament positive for $50 \%$ of cortical cells, indicating neuronal differentiation. However, the lineage of these cells may not be final yet, as rats on postnatal d 1 correspond to preterm human infants and are still developing organisms (14).

The distribution of the TUNEL-positive cells, i.e. periventricular in EH and cortical in LH groups, may result from various factors affecting particular regions of the immature brain such as the type, maturity, developmental activity, and metabolic rate of the target cells. Previous observations showed that apoptosis following insults is more prominent in regions undergoing physiologic cell death $(10,15,16)$.

The occurrence of DNA fragmentation $1 \mathrm{wk}$ after the hypotensive episode suggests a late effect of perfusion failure. An interval between the time of the insult and the appearance of apoptosis is observed even in cultured cells deprived of trophic factors. A more protracted process can be expected in the living organism due to the effect of multiple compensatory mechanisms, or because the observed apoptosis is secondary to the death of afferent/efferent cells that has occurred earlier (17). Indeed, apoptotic cells can be detected for days or weeks after the hypoxic-ischemic insult, peaking at $2 \mathrm{wk}$ in adult rat thalamus or for up to $5 \mathrm{~d}$ after mechanical trauma to the immature rat brain $(16,18)$. This may also be the case for our model, and sequential examination of the fetal brain is needed to determine the time course of posthypotension events.

The clinical effects of the findings described in this study are unknown at present. Hypotensive episodes are not uncommon in pregnant women. It generally is speculated that cognitive or behavioral disorders of childhood that are not associated with gross cerebral malformations might be related to microscopical abnormalities of the brain tissue. Investigations of the clinical effects, by allowing these pups to survive and examining their learning tasks and their cerebral structure at later ages, are currently under way.

\section{REFERENCES}

1. Ornoy A, Benady S, Kohen-Raz R, Russell A 1975 Association between maternal bleeding during gestation and congenital anomalies of the offspring. Am J Obstet Gynecol 124:474-478

2. Sanner G 1979 Pathogenetic and preventive aspects of non-progressive ataxic syndromes. Dev Med Child Neurol 21:663-671

3. Evrard P, Belpaire MC, Boog G, Elkhazen N, Gadisseux JF, LeMarec B, Misson JP, Santini JJ, Van Lierde M 1985 Diagnostic anténatal des affections du systeme nerveux central: résultats préliminaires d'une étude multicentrique européenne. J Fr Echocardiogr 2:123-126

4. Gavrieli Y, Sherman Y, Ben-Sason SA 1992 Identification of programmed cell death in situ via specific labeling of nuclear DNA fragmentation. J Cell Biol 119:493-501

5. Burek MJ, Oppenheim RW 1996 Programmed cell death in the developing nervous system. Brain Pathol 6:427-446

6. Brann AW, Myers RE 1975 Central nervous system findings in the newborn monkey following severe in utero partial asphyxia. Neurology 25:327-338

7. Keunen H, Blanco CE, van Reempts JLH, Hasaart THM 1997 Absence of neuronal damage after umbilical cord occlusion of 10,15, and 20 minutes in midgestation fetal sheep. Am J Obstet Gynecol 176:515-520

8. Bonfoco E, Kraine D, Ankarcrona M, Nicotera P, Lipton SA 1995 Apoptosis and necrosis: two distinct events induced, respectively, by mild and intense insults with $\mathrm{N}$-methyl-D-aspartate or nitric oxide/superoxide in cortical cell cultures. Proc Nat Acad Sci U S A 92:7162-7166

9. Luciano R, Zuppa AA, Maragliano G, Gallini F, Tortorolo G 1997 Fetal encephalopathy after maternal anaphylaxis: case report. Biol Neonate 71:190-193

10. Sidhu RS, Turo UI, Del Bigio MR 1997 Nuclear condensation and fragmentation following cerebral hypoxia-ischemia occurs more frequently in immature than older rats. Neurosci Lett 223:129-132

11. Oppenheim RW 1991 Cell death during development of the nervous system. Annu Rev Neurosci 14:453-501

12. Bennett GS, DiLullo C 1985 Transient expression of a neurofilament protein by replicating neuroepithelial cells of the embryonic chick brain. Dev Biol 107:107-127

13. McConnell SK 1988 Development and decision-making in the mammalian cerebral cortex. Brain Res 47:21-23

14. Roohey T, Raju TNK, Moustogisannis AN 1997 Animal models for the study of perinatal hypoxic-ischemic encephalopathy: a critical analysis. Early Hum Dev 47:115-146

15. Yue X, Mehmet H, Penrice J, Cooper C, Cady E, Wyatt JS, Reynolds EOR, Edwards $\mathrm{AD}$, Squier MV 1997 Apoptosis and necrosis in the newborn piglet brain following transient cerebral hypoxia-ischemia. Neuropathol Applied Neurobiol 23:16-25

16. Bittigau P, Siftinger M, Pohl D, Stadthaus D, Ishimaru M, Shimizu H, Ikeda M, Lang D, Speer A, Olney JW, Ikonomidou C 1999 Apoptotic neurodegeneration following trauma is markedly enhanced in the immature brain. Ann Neurol 45:724-35

17. Johnson EM, Deckwerth TL, Deshmukh M 1996 Neuronal death in developmental models: possible implications in neuropathology. Brain Pathol 6:397-409

18. Conti AC, Raghupati R, Trojanowski JQ, McIntosh TK 1998 Experimental brain injury induces regionally distinct apoptosis during the acute and delayed posttraumatic period. J Neurosci 18:5663-5672 